\title{
Expression of HIF-1a and VEGF in feline mammary gland carcinomas: association with pathological characteristics and clinical outcomes
}

Bo Chen ${ }^{1}$, Susanne Je-Han Lin ${ }^{1}$, Wen-Ta Li ${ }^{1}$, Hui-Wen Chang ${ }^{1}$, Victor Fei Pang ${ }^{1}$, Pei-Yi Chu ${ }^{3}$, Chin-Cheng Lee ${ }^{4}$, Hiroyuki Nakayama ${ }^{5}$, Ching-Ho Wu ${ }^{2^{*}}$ and Chian-Ren Jeng ${ }^{1 *}$ (D)

\begin{abstract}
Background: The microenvironment within solid malignant tumors, including feline mammary gland carcinomas (FMGCs), is commonly hypoxic, possibly due to the lack of functional blood vessels in rapidly proliferating neoplastic tissue. Malignant cells can undergo genetic and adaptive changes that prevent them from dying due to oxygen deprivation through expressions of hypoxia-inducible factor 1 alpha (HIF-1a) and vascular endothelial growth factor (VEGF). Therefore, HIF-1a and VEGF are ideal biomarkers for cancer therapy and prognostic evaluation. The aims of this study were to evaluate the expression of HIF-1a and VEGF in feline mammary carcinomas and analyze their correlations with clinical and pathological factors, such as clinical stage, histologic grading, regional metastasis, and overall survival rate.

(Continued on next page)
\end{abstract}

\footnotetext{
* Correspondence: chinghowu@ntu.edu.tw; crjeng@ntu.edu.tw

${ }^{2}$ Institute of Veterinary Clinical Science, School of Veterinary Medicine, National Taiwan University, Taipei, Taiwan

${ }^{1}$ Graduate Institute of Molecular and Comparative Pathobiology, National Taiwan University, Taipei, Taiwan

Full list of author information is available at the end of the article
}

(c) The Author(s). 2020 Open Access This article is licensed under a Creative Commons Attribution 4.0 International License, which permits use, sharing, adaptation, distribution and reproduction in any medium or format, as long as you give appropriate credit to the original author(s) and the source, provide a link to the Creative Commons licence, and indicate if changes were made. The images or other third party material in this article are included in the article's Creative Commons licence, unless indicated otherwise in a credit line to the material. If material is not included in the article's Creative Commons licence and your intended use is not permitted by statutory regulation or exceeds the permitted use, you will need to obtain permission directly from the copyright holder. To view a copy of this licence, visit http://creativecommons.org/licenses/by/4.0/. The Creative Commons Public Domain Dedication waiver (http://creativecommons.org/publicdomain/zero/1.0/) applies to the data made available in this article, unless otherwise stated in a credit line to the data. 


\begin{abstract}
(Continued from previous page)
Results: Paraffin-embedded tissue samples collected from 72 cats with FMGCs were retrospectively studied. Histologic pattern and histologic grading (Elston and Ellis grading system) of these FMGCs were determined. Our data indicated that grade II tubulopapillary carcinomas $(43 / 72,59.7 \%)$ prevailed in this study, and most FMCGs showed apparent necrosis, squamous metaplasia, and intratumoral stromal response. According to the results of immunohistochemical (IHC) stainings performed in tissue microarrays (TMAs), HIF-1a and VEGF overexpressions were respectively noted in 69.4\% (50/72) and 77.8\% (56/72) of FMGC cases. Chi-square test showed no correlation of HIF-1a overexpression with clinical and pathological factors. VEGF overexpression was significantly correlated with histologic pattern $(p=0.021)$, stromal response $(p=0.048)$, squamous metaplasia $(p=0.001)$, and lymphovascular invasion $(p=0.007)$. However, neither HIF-1a nor VEGF overexpression was correlated with histologic grading and metastasis. Of 38 cats with 1-year follow-up, IHC stainings of HIF-1a and VEGF were performed on whole tissue sections. The results showed that overexpression of HIF-1a was significantly correlated with the overall survival rate $(p<0.05)$ (log-rank test), whereas there was no significant correlation between VEGF overexpression and overall survival rate.
\end{abstract}

Conclusions: This study suggests that the overexpression of HIF-1a may indicate poor prognosis/overall survival rate in cats with FMGCs. Developing compounds that inhibit HIF-1 a may be a potential approach to FMGC treatment.

Keywords: Feline, Mammary gland carcinoma, Hypoxia-inducible factor 1 alpha (HIF-1a), Vascular endothelial growth factor (VEGF)

\section{Background}

Mammary neoplasia is the third most common neoplasia affecting female cats [1]. Feline mammary gland carcinomas are frequently reported with local recurrence and distant metastasis, resulting a high mortality rate [2]. Based on clinical and pathological similarities between FMGCs and human breast cancers, FMGCs have been considered an excellent animal model for the human counterpart [3, 4]. Several clinical and pathological parameters are prognostic for both human breast cancers and FMGCs [5]. Immunohistochemical (IHC) staining is emerging as a method for understanding the molecular pathogenesis of FMGCs, and such understanding may further contribute to FMGC therapies and comparable research on human breast cancers.

A hypoxic microenvironment is frequently present in many solid malignant tumors, including FMGCs. It may be due to the lack of functional blood vessels in rapidly proliferating neoplastic tissue [6]. A prolonged and severely hypoxic condition is usually fatal for neoplastic cells, and thus they will undergo genetic and adaptive changes to accommodate the hypoxic condition [7, 8]. Furthermore, several previous studies have demonstrated that an insufficient level of cellular oxygen is significantly correlated with carcinogenesis, cancerous invasion/metastasis and cell death [8-10].

Hypoxia-inducible factor 1-alpha (HIF-1 $\alpha$ ) plays a crucial role in neoplastic cells responding to low-oxygen tension in a variety of physiologic processes, including angiogenesis, tumorigenesis and metastasis [11, 12]. After neoplastic cells are exposed to hypoxia, the amount of HIF- $1 \alpha$ heterodimerization with the HIF- $1 \beta$ protein (ARNT) rapidly increases, leading to increases in the HIF-1 protein in the nucleus/cytoplasm [13, 14]. The amount of HIF- $1 \alpha$ protein in the nucleus indicates the functional activity of the HIF-1 complex, which may alter the genetic transcription involving angiogenesis, including vascular endothelial growth factor (VEGF) [14]. VEGF overexpression is correlated with the degree of tumor vascularization, tumor progression and diagnosis in many human breast cancers [15]. Furthermore, HIF$1 \alpha$ and VEGF are novel biomarkers for cancer therapy and have led to a great shift in drug development.

In veterinary pathology, although VEGF has been documented as a good prognostic marker for FMGCs, some previous studies have demonstrated inconsistent findings [16-19]. Furthermore, no studies on the overexpression of HIF-1 $\alpha$ in FMGCs have been reported. Therefore, the aims of the present study were (1) to construct FMGC tissue microarrays (TMAs) from the archives for the period of January 2015 to December 2015 at the Graduate Institute of Molecular and Comparative Pathobiology, National Taiwan University, (2) to immunohistochemically investigate the overexpression of HIF- $1 \alpha$ and VEGF in FMGCs, and (3) to evaluate whether the overexpression of VEGF and/or HIF-1 $\alpha$ is significantly correlated with clinical and pathological factors, such as clinical stage, histologic grading, regional metastasis, and overall survival rate.

\section{Results}

\section{Clinical and pathological information on the cases of FMGCs}

Of the 72 feline mammary carcinoma tissues obtained, 45 cases were from spayed females and 3 were from males ( 1 intact and 2 castrated). The median age was $11.6 \pm 3.04$ (4-19). No patients had history of 
chemotherapy or radiotherapy during the survey. On the basis of histologic pattern, tubulopapillary carcinoma was the most common pattern of FMGCs (52/72, 72.2\%), followed by solid carcinoma (10/72, 13.9\%), cribriform (6/ $72,8.3 \%)$, and micropapillary invasive carcinoma (4/72, 5.6\%). Lymphovascular invasion was found in $48.6 \%$ (35/ 72) of the cases. The results of histologic grading demonstrated that grade II FMGCs $(59.7 \%, 43 / 72)$ prevailed in this study. Sixteen of the 26 submitted lymph nodes had metastasis. In addition, most cases had obvious necrosis, squamous differentiation, and intratumoral stromal response.

Overexpression and pattern of HIF-1 $a$ and VEGF in FMGCs HIF-1 $\alpha$ overexpression was detected in $69.4 \%$ (50/72) of the FMGC cases by using constructed TMAs. The positive signals of HIF- $1 \alpha$ in neoplastic cells were mainly nuclear, but mixed nuclear/cytoplasmic positivity was occasionally noted. Neoplastic cells with HIF-1 $\alpha$ overexpression were scattered throughout the neoplasm and frequently observed nearby the necrosis (Fig. 1a, b). VEGF overexpression was observed in $77.8 \%(56 / 72)$ of the FMGC cases. Cytoplasmic VEGF positive signals were noted in neoplastic cells and occasionally observed in stromal cells (Fig. 1c, d). IHC stainings of HIF- $1 \alpha$ and VEGF from 38 FMGC cases with 1-year followup were performed on whole tissue sections, and overexpressions of HIF- $1 \alpha$ and VEGF were noted respectively in $78.9 \%$ $(30 / 38)$ and $89.5 \%(34 / 38)$ of the FMGC cases.

\section{Correlations between HIF-1a/VEGF overexpression and clinical/pathological factors}

The correlations between HIF-1 $\alpha /$ VEGF overexpression and clinical/pathologic characteristics are summarized in Table 1. There were no significant correlations between HIF- $1 \alpha$ expression and clinical/pathological factors. VEGF overexpression was significantly correlated with histologic pattern $(p=0.021$, Chi-square), stromal response ( $p=0.048$, Chi-square), squamous differentiation $(p=0.001$, Chi-square), and lymphovascular invasion ( $p=0.007$, Chi-square). VEGF overexpression was observed in all solid carcinomas $(n=10)$. VEGF overexpression was not correlated with other clinical and pathological parameters, including age, reproductive status, clinical stage, tubule formation, mitotic count, necrosis, lymph node metastasis, and histologic grading. Spearman analysis indicated that the HIF- $1 \alpha$ overexpression was not statistically correlated with VEGF overexpression $(p=0.057, \mathrm{r}=0.226)$ in FMGCs.

\section{Correlation between pathological factors and overall survival rate}

Thirty-eight of the 72 cases had 1-year follow-up. Twelve patients were still alive and 26 were dead. Therefore, the 1-year overall survival rate for all patients was 31.6\% (12/38). In this study, the Elston and Ellis (EE) and Revised Elston and Ellis (REE) grading systems had prognostic significance

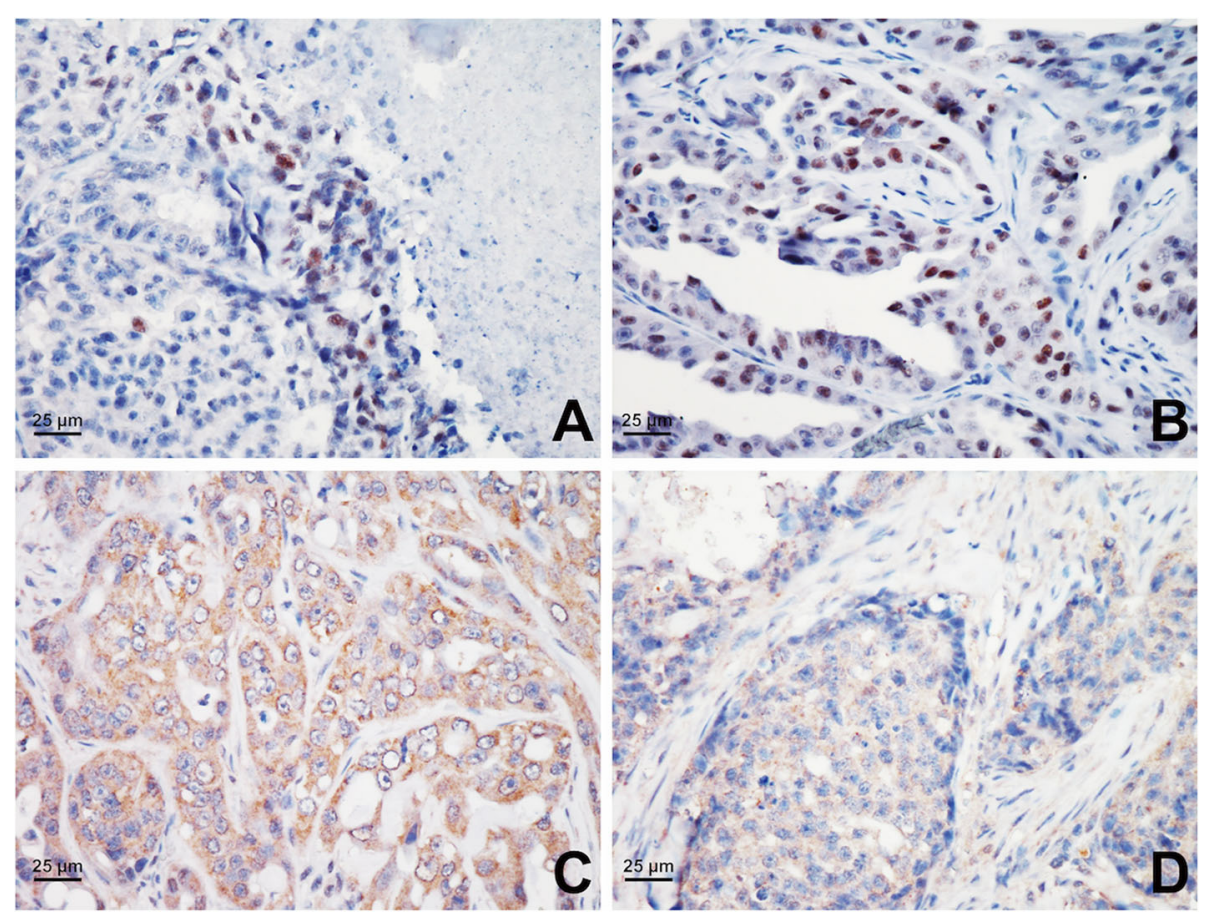

Fig. $1 \mathrm{HIF-1}$ a and VEGF immunohistochemical expression in feline mammary gland carcinomas (FMGCs). a. Perinecrotic pattern of HIF-1 a expression, b. Diffuse pattern of HIF-1a expression, c. Cytoplasmic VEGF expression, d. Cytoplasmic VEGF expression in neoplastic epithelial cells and mesenchymal stromal cells of FMGCs. Magnification, $\times 40$ (panels a-d) 
Table 1 Association between HIF-1a or VEGF and clinical/pathological factors by using TMAs

\begin{tabular}{|c|c|c|c|c|c|}
\hline \multirow[t]{2}{*}{ Factors } & \multirow{2}{*}{$\begin{array}{l}\text { No. of } \\
\text { patients }\end{array}$} & \multicolumn{2}{|l|}{ HIF-1a } & \multicolumn{2}{|l|}{ VEGF } \\
\hline & & Overexpression & $p$ value & Overexpression & $p$ value \\
\hline \multicolumn{6}{|l|}{ Age } \\
\hline$<12 y$ & 32 & 19 & ns & 24 & ns \\
\hline$\geq 12 y$ & 40 & 31 & & 32 & \\
\hline \multicolumn{6}{|l|}{ Reproductive status } \\
\hline Intact female & 24 & 13 & ns & 18 & ns \\
\hline Spayed female & 45 & 34 & & 36 & \\
\hline Intact male & 1 & 1 & & 1 & \\
\hline Castrated male & 2 & 2 & & 1 & \\
\hline \multicolumn{6}{|l|}{ Clinical stage } \\
\hline $\mid+\|$ & 34 & 20 & ns & 20 & ns \\
\hline$I I I+I V$ & 35 & 28 & & 34 & \\
\hline \multicolumn{6}{|l|}{ Pattern } \\
\hline Tubulopapillary & 52 & 37 & ns & 41 & $0.021^{*}$ \\
\hline Solid & 10 & 7 & & 10 & \\
\hline Cribriform & 6 & 4 & & 2 & \\
\hline Invasive micropapillary & 4 & 2 & & 3 & \\
\hline \multicolumn{6}{|l|}{ Tubule formation } \\
\hline$>75 \%$ & 39 & 27 & ns & 28 & ns \\
\hline $10-75 \%$ & 22 & 17 & & 19 & \\
\hline$<10 \%$ & 11 & 6 & & 9 & \\
\hline \multicolumn{6}{|l|}{ Mitotic count } \\
\hline$\leq 20$ & 36 & 25 & ns & 29 & ns \\
\hline$>20$ & 36 & 25 & & 27 & \\
\hline \multicolumn{6}{|l|}{ Necrosis } \\
\hline$\leq 25 \%$ & 32 & 21 & ns & 26 & ns \\
\hline$>25 \%$ & 40 & 29 & & 30 & \\
\hline \multicolumn{6}{|l|}{ Stromal response } \\
\hline Mild & 11 & 6 & ns & 6 & $0.048^{*}$ \\
\hline Peritumoral & 12 & 10 & & 8 & \\
\hline Intratumoral & 49 & 34 & & 42 & \\
\hline \multicolumn{6}{|l|}{ Squamous differentiation } \\
\hline$\leq 5 \%$ & 27 & 17 & ns & 15 & $0.001^{*}$ \\
\hline$>5 \%$ & 44 & 34 & & 41 & \\
\hline \multicolumn{6}{|l|}{ Lymphovascular invasion } \\
\hline Absent & 37 & 17 & ns & 24 & $0.007^{*}$ \\
\hline Present & 35 & 31 & & 32 & \\
\hline \multicolumn{6}{|l|}{ Lymph node metastases } \\
\hline Absent & 10 & 6 & ns & 6 & ns \\
\hline Present & 16 & 10 & & 14 & \\
\hline \multicolumn{6}{|l|}{ EE grading system } \\
\hline Grade 1 & 18 & 13 & ns & 14 & ns \\
\hline Grade 2 & 43 & 31 & & 31 & \\
\hline Grade 3 & 11 & 6 & & 11 & \\
\hline
\end{tabular}


Table 1 Association between HIF-1a or VEGF and clinical/pathological factors by using TMAs (Continued)

\begin{tabular}{|c|c|c|c|c|c|}
\hline \multirow[t]{2}{*}{ Factors } & \multirow{2}{*}{$\begin{array}{l}\text { No. of } \\
\text { patients }\end{array}$} & \multicolumn{2}{|l|}{ HIF-1a } & \multicolumn{2}{|l|}{ VEGF } \\
\hline & & Overexpression & $p$ value & Overexpression & $p$ value \\
\hline \multicolumn{6}{|c|}{ REE grading system } \\
\hline Grade 1 & 40 & 29 & ns & 27 & ns \\
\hline Grade 2 & 28 & 19 & & 25 & \\
\hline Grade 3 & 4 & 2 & & 4 & \\
\hline \multicolumn{6}{|c|}{ Novel grading system } \\
\hline Grade 1 & 5 & 4 & ns & 3 & ns \\
\hline Grade 2 & 30 & 23 & & 20 & \\
\hline Grade 3 & 37 & 23 & & 33 & \\
\hline
\end{tabular}

$*, p<0.05$

ns Not significant

for FMGCs $(p=0.001$, log-rank test, Fig. 2c). Necrosis $(p=$ 0.035 , log-rank test), stromal response $(p=0.030$, log-rank test) and squamous metaplasia ( $p=0.015$, log-rank test) were significantly associated with prognosis. However, there was no significant correlation between lymphovascular invasion and overall survival rate ( $p>0.05$, log-rank test, Fig. $2 \mathrm{~d})$.

\section{Correlation between HIF-1a/VEGF overexpressions and overall survival rate}

HIF- $1 \alpha$ and VEGF overexpressions were demonstrated in $65.8 \%(25 / 38)$ and $76.3 \%(29 / 38)$ of the FMGCs by using TMAs. Furthermore, the IHC stainings of HIF- $1 \alpha$ and VEGF on whole tissue sections indicated HIF- $1 \alpha$ and VEGF overexpressions in $78.9 \%(30 / 38)$ and $89.5 \%$ (34/38) of the FMGCs, respectively.

There was a significant correlation between HIF-1 $\alpha$ overexpression and overall survival rate. When whole tissue sections were used, the 1-year overall survival rates for FMGC cases with and without HIF-1 $\alpha$ overexpression were respectively $80 \%(24 / 30)$ and $25 \%(2 / 8)$ ( $p=0.033$, log-rank test, Fig. $2 \mathrm{c}$ ), but no significant correlation between HIF- $1 \alpha$ overexpression and OS rate was found with TMAs ( $p=0.086$, log-rank test). The 1 year overall survival rates for FMGC cases with and without VEGF overexpression were $70.0 \%(24 / 34)$ and $40.0 \%(2 / 4)$ in the whole sections. No significant
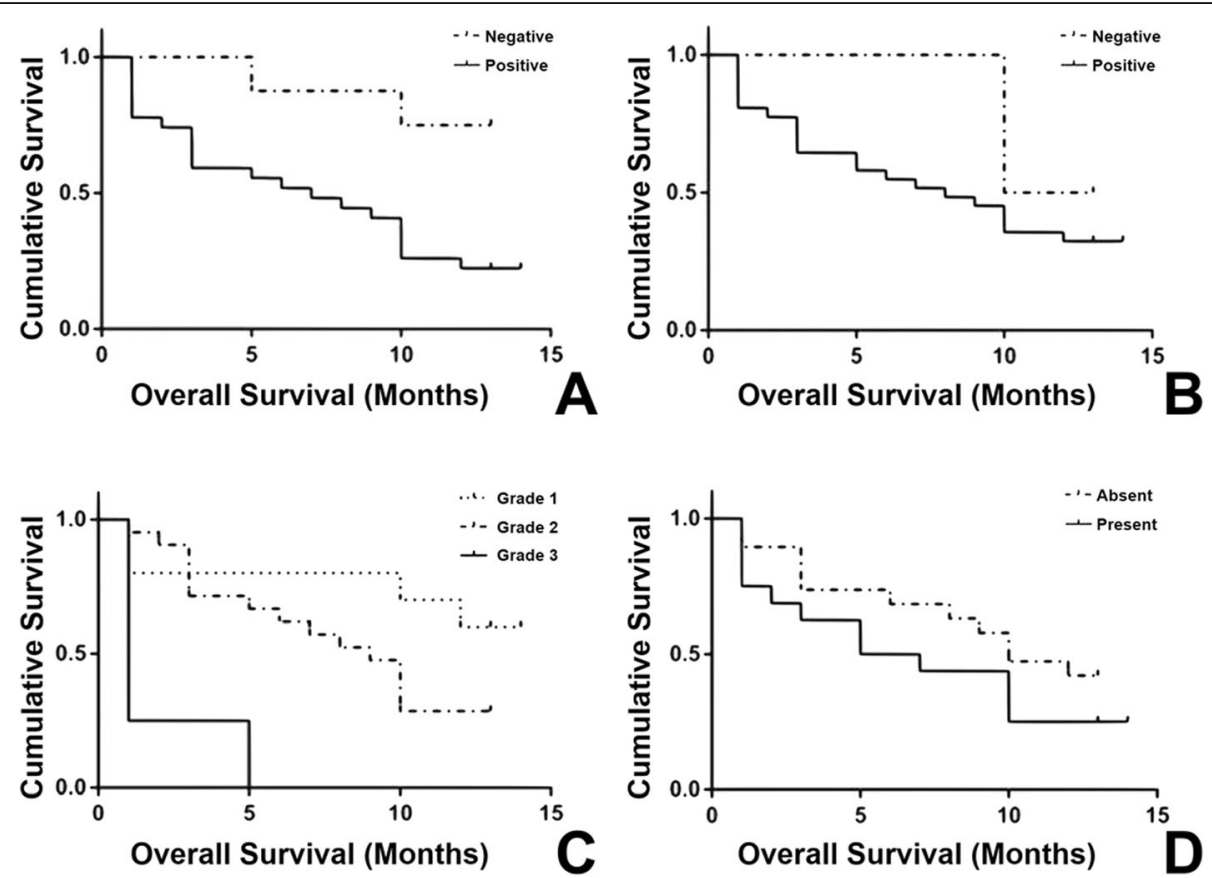

Fig. 2 Kaplan-Meier curves of overall survival rate for 38 cats with mammary gland carcinoma using whole tissue sections. a. Cats with HIF-1 a overexpression had a significantly lower overall survival rate compared with those with HIF-1 a without overexpression. b. VEGF overexpression was not correlated with the overall survival rate of cats with FMGCs. c. Elston and Ellis grading system was significantly correlated with overall survival rate. d. No significant correlation between lymphovascular invasion and lower overall survival rate 
correlation between VEGF overexpression and overall survival rate was found either by TMAs ( $p=0.617$, logrank test) or whole tissue sections $(p=0.285, \log$-rank test, Fig. 2d).

\section{Discussion}

Several studies have demonstrated that tumor hypoxia through activation of angiogenesis assists in tumor progression and metastasis, which also makes solid tumors resistant to radiation and chemotherapy [20]. HIF- $1 \alpha$ is a marker of hypoxia, which activates gene encoding glucose transporters, glycolytic enzymes, and VEGF [14]. It is widely accepted and confirmed in humans that HIF$1 \alpha$ causes the angiogenic switch via VEGF [14]. This retrospective study evaluated the overexpressions of HIF- $1 \alpha$ and VEGF in FMGCs and investigated the correlations among the overexpressions of HIF-1 $\alpha / \mathrm{VEGF}$, clinical/pathological factors, and clinical outcomes.

HIF- $1 \alpha$ has been found to be overexpressed in a variety of human cancers, such as colon, breast, gastric, lung, skin, ovarian, pancreatic, prostate, and renal carcinomas [21-23]. In humans, the amount of HIF-1 $\alpha$ is higher in primary and metastatic neoplasms than in the respective non-neoplastic tissues. To the best of our knowledge, this is the first IHC study of HIF-1 $\alpha$ in FMGCs. Our study demonstrated that $69.4 \%$ (50/72) of the FMGCs had HIF-1 $\alpha$ overexpression. VEGF has been studied in many human neoplasms, such as lung, breast, gastrointestinal tract, renal, and ovarian carcinomas [2428]. A humanized anti-VEGF monoclonal antibody (bevacizumab; Avastin) has been approved as a first-line treatment for metastatic colorectal cancer in humans [29]. In our case, VEGF was positive in $77.8 \%$ (56/72) of the FMGCs. As noted above, HIF- $1 \alpha$ and VEGF overexpressions in FMGCs are not uncommon.

The positive signals of HIF- $1 \alpha$ were diffusely distributed throughout the FMGC or restricted to perinecrotic neoplastic cells, consistent with the pattern of HIF- $1 \alpha$ in human breast cancers [30]. In addition, our results of univariate analysis (Kaplan-Meier) demonstrated that HIF- $1 \alpha$ overexpression was significantly correlated with a lower overall survival rate and considered a potential prognostic factor in FMGCs. This finding is consistent with previous studies of human breast cancers [31-35]. In this study, we used a threshold ( $>0 \%$ positive nuclei/ 5 representative high power fields) for HIF- $1 \alpha$ that was different from the thresholds $(>1 \%$, or $>10 \%$ positive nuclei/ 5 representative high power fields) used in previous studies conducted in humans [30, 31, 36-39]. Furthermore, there is no significant association between overall survival rate and HIF- $1 \alpha$ overexpression in FMGCs if the thresholds for HIF- $1 \alpha$ ( $>1 \%$, or $>10 \%$ positive nuclei/5 representative high power fields) are used. According to this finding, $>0 \%$ is considered an optimal prognostic threshold for FMGCs. VEGF overexpression was not found to be significantly correlated with overall survival rate in this study, which is consistent with some of the previous studies of FMGCs [1619]. A previous study has demonstrated that VEGF overexpression is significantly correlated with clinical outcome [16]. However; the prognostic threshold for VEGF is $72.1 \%$, which is not a conventional method to evaluate the result of VEGF expression [16]. Therefore, a more conventional scoring principle to evaluate VEGF expression, one used in recent studies in FMGCs and human breast cancers, was chosen in this study $[19,40]$.

The correlation between HIF- $1 \alpha$ and VEGF overexpressions was not significant in the present study. Previous studies have suggested that HIF-1 $\alpha$ overexpression can occur in an early stage of breast cancer (before the presence of angiogenesis or invasion) [8,36]. Therefore, it is speculated that the regulation of HIF- $1 \alpha$ and VEGF expressions in FMGCs may be more complicated than or different from that in humans. Although the expression of VEGF is up-regulated during hypoxia by HIF- $1 \alpha$, the significant correlation between their IHC stainings is still controversial in previous human studies of gastric cancer, non-small cell lung cancer, and esophageal carcinoma [41-43]. They have pointed out that factors other than HIF- $1 \alpha$ can regulate VEGF expression [4143]. Many factors such as hormones, cytokines and cellular stress can regulate VEGF transcription as well [44].

The advantages of using TMAs include costeffectiveness and rapid simultaneous molecular profiling of tissue samples from large cohorts. However, few studies have used TMAs in feline tissue $[45,46]$. The weakness of TMAs is the relatively small size of samples, and thus the representativeness may vary among different samples. TMAs can be a useful method to detect VEGF expression in FMGCs because it tends to be large-scale. However, the use of TMAs for evaluating the HIF-1 $\alpha$ expression in FMGCs may be limited due to the low expression level and the restrictive tissue distribution (such as perinecrotic tissue) of HIF- $1 \alpha$. Most importantly, TMAs are usually constructed by taking the most representative areas without marked necrosis or inflammation to reserve more neoplastic cells, and it may conflict with the expression pattern of HIF- $1 \alpha$, which is usually perinecrotic distribution. Therefore, the whole tissue sections of 38 cats with 1-year follow-up were used for investigating the correlation between HIF-1 $\alpha$ overexpression and overall survival rate.

Several prognostic indexes for FMGCs have been advanced in previous studies, including clinical stage, tumor grading, and proliferation markers [5, 47]. In general, veterinary pathologists follow the World Health Organization morphological classification of feline mammary tumor to categorize the histologic types of FMGCs, 
but no significant correlation between histologic type and prognosis has been indicated, except the invasive micropapillary carcinoma [48, 49]. A previous study has demonstrated that invasive micropapillary carcinomas have a distinct histologic pattern with more aggressive biological behavior and poor clinical outcome [49]. Although this statement cannot be supported in this study due to the small sample size $(n<5)$, the cats with invasive micropapillary carcinomas were all dead within 1 year, and thus the 1-year overall survival rate was $0 \%$.

The EE grading system is a gold standard for the histologic grading of human breast cancers, but it may be of limited utility in FMGCs [50]. The Revised EE (REE) and the novel grading system for FMGC have been advanced for their prognostic value of histologic grading [50]. Although the REE grading system is prognostic for FMGCs, no significant correlation between the novel grading system and overall survival rate was indicated in our study. Therefore, it is presumed that the correlation between pathological factors and prognosis may be different in different countries and feline breeds. Therefore, to determine or predict the prognosis of cats with FMGCs, all clinical/ pathological parameters should be of concern.

In conclusion, this study suggests that the overexpression of HIF-1 $\alpha$ indicates poor prognosis in cats with FMGCs. HIF-1 $\alpha$ might therefore be a useful biomarker for feline cancer therapy and prediction of the clinical outcome, and thus developing compounds that inhibit HIF$1 \alpha$ may be a potential approach to FMGCs treatment. In addition, there are some limitations in this study. Two major concerns are 1) the sample size in this study is relatively small. 2) the nature of this study is retrospective and our results are still preliminary. Thus, further investigations on the mRNA expression levels of HIF- $1 \alpha$ and VEGF by RNAscope technology and other molecules involved in their upstream and downstream of the signaling pathway based on an bigger sample size are warranted to determine the potential molecular pathogenesis of FMGCs.

\section{Conclusions}

This is the first study that investigates the expression and the prognostic significance of HIF- $1 \alpha$ in feline mammary carcinomas. The results showed that overexpression of HIF$1 \alpha$ was significantly correlated with the overall survival rate, whereas there was no significant correlation between VEGF overexpression and overall survival rate. Given the major role of HIF- $1 \alpha$ in compensating for oxygen deficiency by increasing availability of oxygen or providing metabolic adaptation of tumor cells, the inhibition of this activity might provide a potential approach to FMGC treatments.

\section{Methods}

The FMGCs used in this study were obtained from the archives of the Graduate Institute of Molecular and
Comparative Pathobiology, National Taiwan University. The samples were surgically obtained by mastectomy or block dissection from cats of different breeds $(n=72)$. Formalin-fixed and paraffin wax-embedded tissue blocks were prepared and available as hematoxylin and eosin (HE)-stained sections. Clinical data including age, reproductive status, and clinical stage were obtained [51]. All of the FMGC cases included in the study were followed up for at least 1 year after surgery by the referring veterinary surgeons, and the post-operative courses of FMGCs were evaluated. FMGC cases with follow-up were then grouped into 2 distinct outcomes: (1) alive, and (2) tumor-related death/euthanasia. Other conditions, such as lost to follow-up, non-tumor-related death/euthanasia or death/euthanasia of undetermined causes, were excluded in this study.

\section{Histological examination}

Histologic slides were reviewed independently by an assessor, with direct assistance from an experienced veterinary pathologist (Chian-Ren Jeng). FMGCs were classified by different histological patterns, including tubulopapillary, solid, cribriform and micropapillary invasive [49]. In the FMGCs presenting more than one histologic pattern, the most predominant pattern in the tissue sections was chosen.

The histologic grading of FMGCs was determined by using the EE, REE, and novel grading systems [50, 52]. Other information, such as central necrosis, squamous differentiation, stromal response, lymphovascular invasion and the presence of lymph node metastasis, were also documented. Briefly, necrosis and squamous differentiation were classified as 2 separate categories. Necrotic areas of the neoplasm with more than $25 \%$ of necrotic areas were classified as "extensive", while other conditions were regarded as "no to mild". Stromal response was classified subjectively as follows: (1) none to mild, (2) peritumoral, and (3) intratumoral. Changes consistent with squamous differentiation included at least 2 of the following: decreased $\mathrm{N}: \mathrm{C}$ ratio, increased cytoplasmic eosinophilia, increased cell size, and increased angularity of cell margin [50]. Squamous differentiation was classified according to proportion of metaplastic cells in all neoplastic cells and divided in 2 subgroups as $(1) \leq 5 \%,(2)>5 \%$. A tumor was positive for lymphovascular invasion if neoplastic emboli were clearly seen within an endothelium-lined lymphatic and/ or vascular lumens.

\section{Tissue microarray (TMA) construction}

TMAs were prepared by Array Biotechnology Co., Ltd. Cylindrical cores of $1.5 \mathrm{~mm}$ in diameter were taken from tumor areas of paraffin blocks and inserted into the TMA block. Three tissue arrays were constructed at the 
same time and composed of the most representative areas without marked necrosis and/or inflammation [45]. Tumor emboli and metastatic tumors in lymph nodes were also included. The TMA blocks were sectioned at $4 \mu \mathrm{m}$ for subsequent IHC study.

\section{IHC stainings of HIF-1a and VEGF}

IHC analysis was performed by using anti-HIF- $1 \alpha$ (Clone: H1alpha67; diluted 1:200; Abcam, Cambridge, UK) and VEGF antibody (Clone: A-20; diluted 1:100; Santa Cruz Biotechnology, Inc., CA), which had good cross-reactivity with feline tissues $[3,40]$. Tissue sections were deparaffinized in xylene, rehydrated in a graded series of ethanol solutions $(100,100,95$, and $80 \%)$, and then microwaved at $95{ }^{\circ} \mathrm{C}$ for $45 \mathrm{~min}$ for HIF- $1 \alpha$ and 30 min for VEGF in commercial trilogy (Cell Marque, California, USA) for antigen retrieval, and then allowed to cool for $20 \mathrm{~min}$. Slides were incubated in $10 \%$ nonimmune goat serum (Dako Ltd., Ely, UK) diluted by $1 \mathrm{X}$ PBS at room temperature for $30 \mathrm{~min}$. The tissue sections were incubated with anti-HIF- $1 \alpha$ and anti-VEGF antibodies respectively for $1.5 \mathrm{~h}$ and $1 \mathrm{~h}$ at room temperature in a moist chamber. Endogenous peroxidase activity was blocked with a solution of $3 \% \mathrm{H}_{2} \mathrm{O}_{2}$ in methyl alcohol for $10 \mathrm{~min}$. The slides were incubated with secondary antibody REAL Envision Detection System Peroxidase/DAB+, mouse/rabbit (Dako), for $60 \mathrm{~min}$ according to the manufacturer's instructions. The slides were then stained with 3-3'-diaminobenzide tetrahydrochloride for $3 \mathrm{~min}$. Sections were counterstained with Mayer's hematoxylin solution. $1 \mathrm{X}$ TBST was used as washing buffer in the procedure of IHC. Negative control included incubation with nonimmune goat serum instead of primary antibody. Feline tissue known to react with HIF- $1 \alpha$ and human invasive breast carcinoma known to express VEGF were used as positive controls. IHC stainings of HIF-1 $\alpha$ and VEGF were conducted in TMAs of 72 FMGC cases and whole sections of 38 FMGC cases with 1-year follow-up.

\section{Scoring criteria}

The positive signals of IHC stainings for both HIF- $1 \alpha$ and VEGF were scored by using the previous criteria $[19,40]$. HIF-1 $\alpha$ was defined as overexpressed when there were any neoplastic cells with nuclear positivity. The presence of cytoplasmic positivity of HIF- $1 \alpha$ in neoplastic cells was not indicative. The positive signals of VEGF were mainly observed in the cytoplasm of neoplastic cells, and the score was ascertained by consideration of both staining density and intensity as follows: 0 , a complete lack of staining; $1,<50 \%$ positive neoplastic cells with weak staining; 2, weak positive staining in $\geq 50 \%$ of neoplastic cells or strong staining in $<50 \%$ of cells; 3 , strong positive staining in $\geq 50 \%$ of neoplastic cells. VEGF overexpression is defined as a score of 2 and 3 , while VEGF non-overexpression is defined as a score of 0 or 1 .

\section{Statistical analyses}

Statistical analyses were all performed in Prism (GraphPad Sofware, CA, USA) and IBM SPSS statistics version 22.0 (IBM Corp., Armond, NY). The correlation between HIF$1 \alpha /$ VEGF overexpressions and clinical/pathological factors were performed using chi-square tests. Spearman correlation from ranks was used to analyze the correlation between VEGF and HIF-1 $\alpha$. Curves for 1-year overall survival rate were estimated with Kaplan-Meier analysis, and differences between 2 groups were evaluated using the log-rank test for univariate survival analysis. A $p$ value $<0.05$ was considered statistically significant.

\section{Abbreviations}

FMGC: Feline mammary gland carcinoma; HIF-1a: Hypoxia-inducible factor 1 alph; VEGF: Vascular endothelial growth factor; TMA: Tissue Microarray; IHC: Immunohistochemical; WHO: World Health Organization.

\section{Acknowledgements}

The authors would like to thank all their colleagues who participated in this study. Partial of this work had been presented by the same research group and published in the Taiwan Veterinary Journal|Vol. 42, No. 04, pp. 219-258 (2016), Proceedings of the Joint Fall Conference and Zoonosis Workshop of the Chinese Society of Veterinary Science and the Taiwan Association of Veterinary Science and Animal Husbandry (CSVS/TAVSAH), 0A-04.

\section{Authors' contributions}

$\mathrm{BC}$ contributed to the conception and design of the study; contributed to acquisition, analysis, and interpretation of data; drafted the manuscript; and critically revised the manuscript. SJHL, WTL, HWC, VFP and HN contributed to the conception and design of the study, and contributed to the analysis and interpretation of data. PYC and CCL contributed to the acquisition of data. CHW and CRJ contributed to the conception and design of the study; contributed to the acquisition, analysis, and interpretation of data; and critically revised the manuscript. All authors read and approved the final manuscript.

\section{Funding}

The author(s) declared that they received no financial support for their research and/or authorship of this article.

\section{Availability of data and materials}

The datasets generated and/or analyzed during the current study are available from the corresponding author on reasonable request. For more information, please contact the corresponding authors.

\section{Ethics approval and consent to participate}

This study is a retrospective investigation carried out on archived tissue samples of feline mammary gland tumors. The protocol has been reviewed and approved by the Institute Animal Care and Use Committee (IACUC) of National Taiwan University. The IACUC Approval No. is NTU107-EL-00165. Owners gave written informed consent to the use of clinical data and stored biological samples for teaching and research causes.

\section{Consent for publication}

Not applicable.

\section{Competing interests}

The authors declare that no competing interests exist.

\section{Author details}

${ }^{1}$ Graduate Institute of Molecular and Comparative Pathobiology, National Taiwan University, Taipei, Taiwan. ${ }^{2}$ Institute of Veterinary Clinical Science, 
School of Veterinary Medicine, National Taiwan University, Taipei, Taiwan. ${ }^{3}$ Department of Pathology, Show Chwan Memorial Hospital, Changhua, Taiwan. ${ }^{4}$ Department of Pathology, Shin Kong Wu Ho-Su Memorial Hospital Taipei, Taiwan. ${ }^{5}$ Department of Pathology, The University of Tokyo, Tokyo, Japan

Received: 8 April 2019 Accepted: 22 April 2020

Published online: 06 May 2020

\section{References}

1. MacEwen EG, Hayes AA, Harvey HJ, Patnaik AK, Mooney S, Passe S. Prognostic factors for feline mammary tumors. J Am Vet Med Assoc. 1984; 185:201-4.

2. Amorim FV, Souza HJ, Ferreira AM, Fonseca AB. Clinical, cytological and histopathological evaluation of mammary masses in cats from Rio de Janeiro. Brazil J Feline Med Surg. 2006;8:379-88.

3. Zappulli V, De Zan G, Cardazzo B, Bargelloni L, Castagnaro M. Feline mammary tumours in comparative oncology. J Dairy Res. 2005;72:98-106.

4. de las Mulas JM, Reymundo C. Animal models of human breast carcinoma: canine and feline neoplasms. Rev Oncología. 2000;2:274-81.

5. Hughes K, Dobson JM. Prognostic histopathological and molecular markers in feline mammary neoplasia. Vet J. 2012;194:19-26.

6. Dang CV, Semenza GL. Oncogenic alterations of metabolism. Trends Biochem Sci. 1999;24:68-72.

7. Maxwell PH, Wiesener MS, Chang GW, Clifford SC, Vaux EC, Cockman ME, et al. The tumour suppressor protein VHL targets hypoxia-inducible factors for oxygen-dependent proteolysis. Nature. 1999;399:271-5.

8. Zhong H, De Marzo AM, Laughner E, Lim M, Hilton DA, Zagzag D, et al. Overexpression of hypoxia-inducible factor 1alpha in common human cancers and their metastases. Cancer Res. 1999;59:5830-5.

9. Hockel M, Vaupel P. Tumor hypoxia: definitions and current clinical, biologic, and molecular aspects. J Natl Cancer Inst. 2001;93:266-76.

10. Ellis LM, Fidler IJ. Angiogenesis and metastasis. Eur J Cancer. 1996;32A:245160 .

11. Semenza GL. HIF-1: mediator of physiological and pathophysiological responses to hypoxia. J Appl Physiol. 2000;88:1474-80.

12. Tatum JL, Kelloff GJ, Gillies RJ, Arbeit JM, Brown JM, Chao KSC, et al. Hypoxia: importance in tumor biology, noninvasive measurement by imaging, and value of its measurement in the management of cancer therapy. Int J Radiat Biol. 2006;82:699-757.

13. Iyer NV, Kotch LE, Agani F, Leung SW, Laughner E, Wenger RH, et al. Cellular and developmental control of $\mathrm{O} 2$ homeostasis by hypoxia-inducible factor 1 alpha. Genes Dev. 1998;12:149-62.

14. Forsythe JA, Jiang BH, lyer NV, Agani F, Leung SW, Koos RD, et al. Activation of vascular endothelial growth factor gene transcription by hypoxiainducible factor 1. Mol Cell Biol. 1996;16:4604-13.

15. Scully OJ, Bay BH, Yip G, Yu Y. Breast cancer metastasis. Cancer Genomics Proteomics. 2012:9:311-20.

16. Millanta F, Lazzeri G, Vannozzi I, Viacava P, Poli A. Correlation of vascular endothelial growth factor expression to overall survival in feline invasive mammary carcinomas. Vet Pathol. 2002;39:690-6.

17. Millanta F, Silvestri G, Vaselli C, Citi S, Pisani G, Lorenzi D, et al. The role of vascular endothelial growth factor and its receptor Flk-1/KDR in promoting tumour angiogenesis in feline and canine mammary carcinomas: a preliminary study of autocrine and paracrine loops. Res Vet Sci. 2006;81: 350-7.

18. Islam MS, Matsumoto M, Hidaka R, Miyoshi N, Yasuda N. Expression of NOS and VEGF in feline mammary tumours and their correlation with angiogenesis. Vet J. 2012;192:338-44.

19. De Campos CB, Damasceno KA, Gamba CO, Ribeiro AM, Machado CJ, Lavalle $G E$, et al. Evaluation of prognostic factors and survival rates in malignant feline mammary gland neoplasms. J Feline Med Surg. 2016;18: 1003-12.

20. Brown JM. Tumor hypoxia in cancer therapy. Method Enzymol. 2007;435: 297-321.

21. Hockel M, Schlenger K, Aral B, Mitze M, Schaffer U, Vaupel P. Association between tumor hypoxia and malignant progression in advanced cancer of the uterine cervix. Cancer Res. 1996;56:4509-15.

22. Brizel DM, Scully SP, Harrelson JM, Layfield L, Bean JM, Prosnitz LR, et al. Tumor oxygenation predicts for the likelihood of distant metastases in human soft tissue sarcoma. Cancer Res. 1996;56:941-3.
23. Volm M, Koomagi R. Hypoxia-inducible factor (HIF-1) and its relationship to apoptosis and proliferation in lung cancer. Anticancer Res. 2000;20:1527-33.

24. Volm M, Koomagi R, Mattern J. Prognostic value of vascular endothelial growth factor and its receptor Flt-1 in squamous cell lung cancer. Int J Cancer. 1997;74:64-8.

25. Yoshiji H, Gomez DE, Shibuya M, Thorgeirsson UP. Expression of vascular endothelial growth factor, its receptor, and other angiogenic factors in human breast cancer. Cancer Res. 1996;56:2013-6.

26. Ellis LM, Takahashi Y, Fenoglio CJ, Cleary KR, Bucana CD, Evans DB. Vessel counts and vascular endothelial growth factor expression in pancreatic adenocarcinoma. Eur J Cancer. 1998;34:337-40.

27. Tomisawa M, Tokunaga T, Oshika Y, Tsuchida T, Fukushima Y, Sato H, et al Expression pattern of vascular endothelial growth factor isoform is closely correlated with tumour stage and vascularisation in renal cell carcinoma. Eur J Cancer. 1999:35:133-7.

28. Sowter HM, Corps AN, Evans AL, Clark DE, Charnock-Jones DS, Smith SK. Expression and localization of the vascular endothelial growth factor family in ovarian epithelial tumors. Lab Investig. 1997;77:607-14.

29. Ferrara N, Hillan KJ, Novotny W. Bevacizumab (Avastin), a humanized antiVEGF monoclonal antibody for cancer therapy. Biochem Biophys Res Commun. 2005:333:328-35.

30. Vleugel MM, Greijer AE, Shvarts A, van der Groep P, van Berkel M, Aarbodem Y, et al. Differential prognostic impact of hypoxia induced and diffuse HIF-1alpha expression in invasive breast cancer. J Clin Pathol. 2005;58:172-7.

31. Dales JP, Garcia S, Meunier-Carpentier S, Andrac-Meyer L, Haddad O, Lavaut $\mathrm{MN}$, et al. Overexpression of hypoxia-inducible factor HIF-1alpha predicts early relapse in breast cancer: retrospective study in a series of 745 patients. Int J Cancer. 2005:116:734-9.

32. Saponaro C, Malfettone A, Ranieri G, Danza K, Simone G, Paradiso A, et al. VEGF, HIF-1alpha expression and MVD as an angiogenic network in familial breast cancer. PLoS One. 2013;8:53070.

33. Yamamoto $Y$, Ibusuki M, Okumura $Y$, Kawasoe $T$, Kai $K$, Iyama $K$, et al. Hypoxia-inducible factor 1alpha is closely linked to an aggressive phenotype in breast cancer. Breast Cancer Res Treat. 2008;110:465-75.

34. Bos R, van der Groep P, Greijer AE, Shvarts A, Meijer S, Pinedo HM, et al. Levels of hypoxia-inducible factor-1alpha independently predict prognosis in patients with lymph node negative breast carcinoma. Cancer. 2003;97:1573-81.

35. Schindl M, Schoppmann SF, Samonigg H, Hausmaninger H, Kwasny W, Gnant $M$, et al. Overexpression of hypoxia-inducible factor 1alpha is associated with an unfavorable prognosis in lymph node-positive breast cancer. Clin Cancer Res. 2002;8:1831-7.

36. Okada K, Osaki M, Araki K, Ishiguro K, Ito H, Ohgi S. Expression of hypoxiainducible factor (HIF-1alpha), VEGF-C and VEGF-D in non-invasive and invasive breast ductal carcinomas. Anticancer Res. 2005;25:3003-9.

37. Pansare V, Munkarah AR, Schimp V, Haitham Arabi M, Saed GM, Morris RT, et al. Increased expression of hypoxia-inducible factor 1alpha in type I and type II endometrial carcinomas. Mod Pathol. 2007;20:35-43.

38. Cao D, Hou M, Guan YS, Jiang M, Yang Y, Gou HF. Expression of HIF-1alpha and VEGF in colorectal cancer: association with clinical outcomes and prognostic implications. BMC Cancer. 2009;9:432

39. Saka B, Ekinci O, Dursun A, Akyurek N. Clinicopathologic and prognostic significance of immunohistochemical expression of HIF-1alpha, CXCR4 and CA9 in colorectal carcinoma. Pathol Res Pract. 2017:213:783-92.

40. Agaoglu OK, Agaoglu AR, Guzeloglu A, Kurar E, Kayis SA, Ozmen O, et al. Expression of hypoxia-inducible factors and vascular endothelial growth factor during pregnancy in the feline uterus. Theriogenology. 2015;84:24-33.

41. Kim SJ, Rabbani ZN, Dewhirst MW, Vujaskovic Z, Vollmer RT, Schreiber EG, et al. Expression of HIF-1alpha, CA IX, VEGF, and MMP-9 in surgically resected non-small cell lung cancer. Lung Cancer. 2005;49:325-35.

42. Oh SY, Kwon HC, Kim SH, Jang JS, Kim MC, Kim KH, et al. Clinicopathologic significance of HIF-1alpha, p53, and VEGF expression and preoperative serum VEGF level in gastric cancer. BMC Cancer. 2008;8:123.

43. Takala H, Saarnio J, Wiik H, Ohtonen P, Soini Y. HIF-1alpha and VEGF are associated with disease progression in esophageal carcinoma. J Surg Res. 2011;167:41-8.

44. Pagès $\mathrm{G}$, Pouysségur J. Transcriptional regulation of the vascular endothelial growth factor gene-a concert of activating factors. Cardiovasc Res. 2005;65: 564-73.

45. Muscatello LV, Sarli G, Beha G, Asproni P, Millanta F, Poli A, et al. Validation of tissue microarray for molecular profiling of canine and feline mammary tumours. J Comp Pathol. 2015;152:153-60. 
46. Takala H, Kauppila JH, Soini Y, Selander KS, Vuopala KS, Lehenkari PP, et al. Toll-like receptor 9 is a novel biomarker for esophageal squamous cell dysplasia and squamous cell carcinoma progression. J Innate Immun. 2011; 3:631-8.

47. Gimenez F, Hecht S, Craig LE, Legendre AM. Early detection, aggressive therapy: optimizing the management of feline mammary masses. J Feline Med Surg. 2010;12:214-24.

48. Misdorp W, Else RW, Hellmén E, Lipscomb TP. Histological classification of mammary tumors of the dog and the cat. Washington, DC: Armed Forces Institute of Pathology in cooperation with the American Registry of Pathology; 1999

49. Seixas F, Palmeira C, Pires MA, Lopes C. Mammary invasive micropapillary carcinoma in cats: clinicopathologic features and nuclear DNA content. Vet Pathol. 2007:44:842-8.

50. Mills SW, Musil KM, Davies JL, Hendrick S, Duncan C, Jackson ML, et al. Prognostic value of histologic grading for feline mammary carcinoma: a retrospective survival analysis. Vet Pathol. 2015;52:238-49.

51. Sorenmo KU, Worley DR, Goldschmidt MH. Tumors of the mammary gland. In: Withrow SJ, Vail DM, editors. Withrow and Macewan's small animal clinical oncology. 5th ed. St. Louis: Saunders Elsevier; 2013. p. 538-56.

52. Elston CW, Ellis IO, Symmers WC. The breast: Vol. 13 in the systemic pathology series. 3rd ed. London: Churchill Livingstone; 1998.

\section{Publisher's Note}

Springer Nature remains neutral with regard to jurisdictional claims in published maps and institutional affiliations.

- fast, convenient online submission

- thorough peer review by experienced researchers in your field

- rapid publication on acceptance

- support for research data, including large and complex data types

- gold Open Access which fosters wider collaboration and increased citations

- maximum visibility for your research: over $100 \mathrm{M}$ website views per year

At $\mathrm{BMC}$, research is always in progress.

Learn more biomedcentral.com/submissions 